Regular article

\title{
Process simulation-integrated optimization of lignocellulolytic enzyme production
}

\author{
Zeynep Yilmaz-Sercinoglu, Nihat Alpagu Sayar* \\ Marmara University, Faculty of Engineering, Department of Bioengineering, Goztepe Campus, 34722, Kadikoy, Istanbul, Turkey
}

\section{H I G H L I G H T S}

- P. sanguineus growth conditions are optimized for Lac, Bet, and Cmc activities.

- A novel workflow integrating experiments and process simulations is offered.

- Kriging is used to model time-profile data from activity measurements.

- The workflow is demonstrated on a bioethanol production process case study.

- Significance of Bet activity favors yeast extract dominated optimal growth medium.

\section{A R T I C L E I N F O}

\section{Keywords:}

Lignocellulolytic enzymes

Bioethanol

Multi-objective optimization

Kriging

Process simulation

\begin{abstract}
A B S T R A C T
An optimization workflow is introduced which integrates multi-objective optimization of lignocellulolytic enzyme cocktail ingredients with a bioethanol production process where the enzymes are utilized. The workflow integrates data collection via exploratory experiments, modeling via Kriging, Pareto-based multi-objective optimization, and process simulation. The critical links in the integration are calculation of enzyme cocktail performance and cost. This allows the identification of the best Pareto-optimal result depending on process simulation results. The workflow is demonstrated on a case study involving the production of lignocellulolytic enzymes laccase, $\beta$-glucosidase, and carboxymethyl cellulase by a white rot fungus, Pycnoporus sanguineus DSMZ 3024. Concentrations of various carbon and nitrogen sources and culture duration are optimized. Two cases are analyzed: i) where all culture conditions and three enzyme activities are assumed to affect enzyme cost and performance equally; ii) where culture duration and $\beta$-glucosidase activity are assumed to respectively affect enzyme cost and performance more significantly compared to the other factors. The integrated optimization workflow identified a shift from a malt extract dominant growth medium in the first case to a yeast extract dominant medium in the second. This shift could not have been identified without the proposed workflow.
\end{abstract}

\section{Introduction}

Production of bioethanol from lignocellulosic feedstock is a promising and potentially sustainable alternative to petroleum-based fuel [1]. Enzymatic bioprocessing of lignocellulosic raw materials is a preferable route compared to alternatives like acid treatment, due to milder operating conditions and simpler downstream processing requirements [2]. However, the high cost of lignocellulolytic enzymes is a major challenge towards the commercialization of such bioprocesses [3]. Techno-economic analyses of bioethanol production processes from various lignocellulosic raw materials illustrate this situation. Enzyme cost contribution to bioethanol selling price has been shown to be as high as $48 \%$ [4] when corn stover is used as feedstock and around 13\% on average [1]. Others have shown enzyme cost to have a considerable effect on operating costs varying around 16 [5] to $19 \%$ [6], when the feedstock is wheat straw and miscanthus, respectively.

As a way to reduce enzyme cost, enzyme improvement for better biomass conversion has been and still is a critical research priority $[7,8]$. Screening and selection of efficient organisms [9] and subsequent optimization of culture conditions for enzyme production [10] are routinely employed approaches towards this goal. Generally, the objective of optimization is achieving maximal lignocellulolytic enzyme activities [7] and preparing an optimal enzyme cocktail which lead to maximum reducing sugar content to be released from the lignocellulosic feedstock for subsequent bioethanol fermentation [11-14]. It is common practice in this area of research to limit the scope of

\footnotetext{
* Corresponding author at: Marmara University, Faculty of Engineering, Department of Bioengineering, Göztepe Campus, 34722, Istanbul, Turkey.

E-mail address: alpagu.sayar@marmara.edu.tr (N.A. Sayar).
} 
publications to report optimal conditions and achieved activities. For example, Prasher and Chauhan (2015) studied the effect of various carbon and nitrogen sources on lignocellulolytic enzyme production by Dictyoarthrinium Synnematicum Somrith where optimal conditions were found for laccase (Lac), manganese peroxidase, and lignin peroxidase [15]. In another study, carboxymethyl cellulase (Cmc) activity was optimized via the consideration of growth medium ingredients such as peptone and yeast extract [16]. More recently, effect of medium ingredients and growth conditions were investigated with a statistical analysis of achieved FPase, Cmc, and $\beta$-glucosidase (Bet) activities [17].

The effect of optimal enzyme production conditions and achievable activities on overall bioethanol production techno-economics is not trivial. A quantitative and computational scheme to relate enzyme production optimization to bioethanol production process design is imperative. It is crucial to realize that enzyme improvement is only one aspect of a multi-faceted and interactive process design and development effort for lignocellulose-derived bioethanol production. Other aspects include feedstock pretreatment, fermentation, and downstream processing. So, enzyme improvement must be considered within a larger context including the conceptual design, modeling and simulation of the complete bioethanol production process utilizing these enzymes $[4,18]$.

Often, bioethanol process design studies incorporate enzyme cost and performance as static assumptions [6], specified targets [19] or uncertain variables [20]. There isn't a dynamic link in any of these examples or similar studies that could computationally propagate the effects of enzyme production optimization on the techno-economics of bioethanol production. The authors of this paper observe a lack of dynamic integration between enzyme improvement and process design workflows. Therefore, a demonstration of concept level workflow is presented in this paper that entertains the idea of process simulationintegrated optimization of lignocellulolytic enzyme production.

In the conventional workflow, once a potential lignocellulolytic enzyme producing organism is identified and characterized, optimization of culture conditions of the selected organism is performed first and independently [21]. Later and separately, results from the enzyme optimization step (preferably quantified in terms of maximum enzyme activities achieved and estimated cost of enzyme production) are used within the conceptual design, modeling, and simulation of a bioethanol production process [5]. This approach can result in a sub-optimal situation since there is no dynamic interaction between experimental results and bioprocess simulations. Without such interactions, marginal improvements in enzyme activities achieved via standalone optimization in the first step may fail to allow feasible bioethanol production in the second step. For instance, a certain set of optimal culture conditions for enzyme production may marginally outperform another set of conditions. However, a possible corresponding elevation in enzyme production costs may be too high to justify the preference of the marginally better option. To quantify the trade-off, cost and performance of the enzymes should be contextually related. A more holistic approach should integrate the effects of changes in enzyme production conditions with the techno-economic performance of the whole bioethanol production process.

In summary, a computational scheme, that is practical and applicable, to integrate the experimental aspects of enzyme improvement with simulations of bioprocesses, where these enzymes are to be utilized, is lacking. This paper aims to present a workflow which demonstrates the abovementioned integrated approach on a case study. The workflow offers a dynamic link between experimentation and bioprocess simulation. Our research group has previously evaluated the white rot fungus Pycnoporus sanguineus DSMZ 3024 for the production of Lac, Bet, and $\mathrm{Cmc}$ as potential ingredients of a lignocellulolytic enzyme cocktail [22]. Also, a bioethanol production process utilizing hazelnut husk $(\mathrm{HH})$ as a lignocellulosic feedstock and the abovementioned enzymes was conceptually designed, modelled, and simulated [23]. In this paper, a demonstration-of-concept level optimization of culture medium ingredients and culture duration for the production of the three enzymes using a process simulation-integrated scheme is presented.

\section{Materials and methods}

The main contribution of the present study to bioethanol process design and development literature is a methodological workflow which integrates early stage exploratory experiments for the optimization of lignocellulolytic enzyme mixture production with bioethanol production process simulations. The workflow is demonstrated on a case study.

The main carbon source in the enzyme production culture medium is $\mathrm{HH}$. Addition of medium components (peptone as nitrogen source, yeast extract as additional carbon and nitrogen source, malt extract as additional carbon and nitrogen source, and sodium nitrate as an inorganic nitrogen source) and culture duration are optimized. A set of exploratory experiments are performed to collect enough data to establish three models to predict the activity of each enzyme under given culture conditions. A multi-objective Pareto optimization [24] of the three enzyme activities is performed to obtain a 21-sample non-dominated Pareto-optimal set of results. Each of the 21 results contains a set of culture condition values (auxiliary ingredient concentrations and culture duration) and accompanying enzyme activities that would be achieved under those conditions. None of the 21 results is superior to the others (it is a non-dominated set of results) meaning that no improvement can be achieved in any one of the three activities without compromising the others.

The critical step of the integrated optimization workflow is the estimation of a pseudo-enzyme cost (EC) based on culture medium composition and duration as well as a pseudo-enzyme cocktail performance metric (biomass conversion efficiency; CE) based on the achieved activities of the three enzymes. These two values are calculated for each of the 21 Pareto-optimal results and subsequently fed into the previously developed process model [23]. The overall process performance is simulated for each Pareto-optimal result. The point in the Pareto optimal set that gives the best process performance is selected as the overall optimal result. The optimization results are not only a function of culture conditions but also the bioethanol production process techno-economics. Process simulation-integrated optimization results are more informative compared to conventional standalone optimization results.

\subsection{Experimental}

\subsubsection{Strain and chemicals}

All of the chemicals and reagents used for experiments were purchased from Sigma unless stated otherwise. P. sanguineus DSMZ 3024 (Leibniz Institute-German Collection of Microorganisms and Cell Culture) was used as lignocellulosic enzyme producing microorganism. $\mathrm{HH}$ was supplied from local producers in northern region of Turkey. $\mathrm{HH}$ was prepared as described in [22] for further use as main carbon source.

\subsubsection{Fungal growth and enzyme production}

Malt extract agar (MEA) was used for fungal growth. MEA was prepared in 11 with the following ingredients: $20 \mathrm{~g}$ malt extract, $5 \mathrm{~g}$ peptone from casein (peptone) and $20 \mathrm{~g}$ agar. Agar medium was sterilized at $121^{\circ} \mathrm{C}, 1 \mathrm{~atm}$ for $15 \mathrm{~min}$. Medium was cooled to $70^{\circ} \mathrm{C}$ and agar plates were poured under laminar hood. Agar plates were inoculated with previously grown fungal cultures (cultures were passaged monthly and kept in $4{ }^{\circ} \mathrm{C}$ for further use). Agar plates were incubated at $37{ }^{\circ} \mathrm{C}$ for 3 days. Spore suspension was prepared as mentioned in an earlier study of our group [22].

Enzyme production medium contained $12 \mathrm{~g} / \mathrm{l} \mathrm{HH}$ and a total of $20 \mathrm{~g} / \mathrm{l}$ additional nitrogen source as detailed in Table $1 . \mathrm{pH}$ was set to 7.0 with $1 \mathrm{M} \mathrm{NaOH}$. $\mathrm{HH}$ was added as the sole carbon source to induce 
Table 1

Enzyme production medium component ranges.

\begin{tabular}{llcc}
\hline Medium Component & \multicolumn{2}{l}{ Concentration Levels (g/L) } \\
\hline Peptone (A) & 0 & 10 & 20 \\
Yeast extract (B) & 0 & 10 & 20 \\
Malt extract (C) & 0 & 10 & 20 \\
Sodium nitrate (D) & 0 & 10 & \\
\hline
\end{tabular}

Independent variables A-D code for medium components in the designed experiments. Additionally, an independent variable E codes for sampling time points $(\mathrm{E}=0-7)$.

lignocellulolytic enzyme production (Lac, Bet, and $\mathrm{Cmc}$ ). Inoculation with spore suspension was done according to [22]. Production was carried out in $500 \mathrm{ml}$ Erlenmeyer flask with $200 \mathrm{ml}$ working volume. Time course of enzyme production was decided depending on the previous works of our group [22] and other groups [25,26]. Submerged production lasted for 7 days with daily sampling, at $30^{\circ} \mathrm{C}$ and $180 \mathrm{rpm}$ in a shaking incubator. All the experiments were done at least in duplicate.

Table 1 shows the concentration ranges of the medium components used in this study. The components and concentrations were selected as an interpretation of the authors' of the present study based on previous optimization studies on P. sanguineus [27] , Pleurotus ostreatus [28], and Phlebia brevispora [29]. The experiments performed were early exploratory investigations to understand the effect of nitrogen sources on the enzyme production. 6 exploratory experiments were designed as tabulated in Table 2.

\subsubsection{Enzyme activity assays}

2.1.3.1. Laccase. Lac activity was measured as described elsewhere [30] with following modifications: $15 \mathrm{mM}$ ABTS (2,2'-Azino-bis(3ethylbenzothiazoline-6-sulfonic acid) diammonium salt was used as substrate. $0.950 \mathrm{ml}$ citrate buffer, $0.05 \mathrm{ml}$ enzyme solution (if dilution was needed, final enzyme volume was kept as $0.050 \mathrm{ml}$ ), $0.2 \mathrm{ml}$ ABTS (dissolved in $0.1 \mathrm{M}$ sodium citrate buffer ( $\mathrm{pH}$ 3.0)) solution were mixed in spectrophotometric cuvette at room temperature for $3 \mathrm{~min}$ and absorbance was read at $420 \mathrm{~nm}$ right after timeout. For blank solution, $\mathrm{t}=0$ sample was used as blank solution. One unit of Lac activity was expressed as the amount of enzyme required to oxidize 1 $\mu$ mole of ABTS in a minute under the assay conditions.

2.1.3.2. $\beta$-glucosidase. Bet activity was measured as described elsewhere [31] with the following modifications: $10 \mathrm{mM}$ pNPG (4Nitrophenyl $\beta$-D-glucopyranoside) was used as substrate. $100 \mu \mathrm{l}$ pNPG solution, $100 \mu$ l enzyme solution (if dilution was needed, final enzyme volume was kept $100 \mu \mathrm{l}) .800 \mu \mathrm{l}$ acetate buffer $(0.1 \mathrm{M}$, pH 4.5) were mixed and the solution was put in water bath $45^{\circ} \mathrm{C}$ for $15 \mathrm{~min}$. After $15 \mathrm{~min}, 1 \mathrm{ml} 1 \mathrm{M} \mathrm{Na}_{2} \mathrm{CO}_{3}$ was added to the tubes to stop reaction. Absorbance was read at $420 \mathrm{~nm}$. One unit of Bet activity was expressed as the amount of enzyme required to release $1 \mu$ mole of pNP (pNitrophenol) per minute under the assay conditions.

2.1.3.3. Carboxymethyl cellulase. Cmc activity was measured as described elsewhere [32] with following modifications: $0.1 \mathrm{ml}$ crude

Table 2

Experimental design.

\begin{tabular}{lllll}
\hline Experiments & $\mathrm{A}(\mathrm{g} / \mathrm{L})$ & $\mathrm{B}(\mathrm{g} / \mathrm{L})$ & $\mathrm{C}(\mathrm{g} / \mathrm{L})$ & $\mathrm{D}(\mathrm{g} / \mathrm{L})$ \\
\hline 1 & 20 & 0 & 0 & 0 \\
2 & 10 & 10 & 0 & 0 \\
3 & 0 & 10 & 10 & 0 \\
4 & 0 & 0 & 20 & 0 \\
5 & 0 & 10 & 0 & 10 \\
6 & 0 & 0 & 0 & 20 \\
\hline
\end{tabular}

enzyme solution and $0.9 \mathrm{ml} 2 \%$ carboxymetylcellulose (dissolved in $0.1 \mathrm{M}$ sodium acetate buffer with $\mathrm{pH} 4.5$ ) were vortexed in a heat resistant glass tube and incubated in $45^{\circ} \mathrm{C}$ water bath for $5 \mathrm{~min} .15 \mathrm{~min}$ later, $3 \mathrm{ml} \mathrm{3,5-dinitrosalicylic} \mathrm{acid} \mathrm{(DNS)} \mathrm{was} \mathrm{added,} \mathrm{then} \mathrm{tubes} \mathrm{were}$ incubated in boiling water for $10 \mathrm{~min}$ and transferred into ice. Absorbance was read at $540 \mathrm{~nm}$ after the sample cooled down to room temperature. One unit of $\mathrm{Cmc}$ activity was expressed as the amount of enzyme required to release $1 \mu$ mole of reducing sugar per minute under the assay conditions.

\subsection{Modeling and optimization}

\subsubsection{Enzyme activity models (Kriging)}

A total of 48 activity data points were acquired for each of the three enzymes from time course experiments. Three empirical models were generated using Kriging [33] which is argued to be a better choice compared to more commonly used response surface models (low order polynomials) for highly nonlinear systems [34]. Our group has shown in a recent publication that Kriging outperforms conventional response surface methodology in the modeling of a complex biodiesel production scheme, using a limited number of exploratory experiments with predominantly temporal data [35].

Conventional response surface model structure is [36]:

$y=f(x)+e$

comprising a low order polynomial and a constant error whereas the Kriging predictor is [33]:

$y=f(x)+z(x)$

comprising a low order polynomial and a stochastic error.

Each model describes and can be used to predict the activity of one the three enzymes as a function of concentrations of medium components and culture duration. DACE Kriging toolbox [37] under MATLAB was used to generate the models.

Activity $=f(A, B, C, D, E)$

\subsubsection{Multi-objective optimization (Pareto)}

Since there are three enzymes of interest being produced, the culture conditions were optimized to obtain the best possible results for three activities; making this a multi-objective optimization problem with the following objective functions:

Activity $_{L a c}=f(A, B, C, D, E)$

Activity $_{\text {Bet }}=f(A, B, C, D, E)$

Activity $_{\mathrm{Cmc}}=f(A, B, C, D, E)$

The multi-objective optimization problem was solved using the genetic algorithm-based multi-objective Pareto optimization functionality under MATLAB. The MATLAB function, gamultiobj (available under Global Optimization Toolbox), was executed with constraints on the independent variables. The objective functions used for Pareto optimization were the Kriging models generated for each enzyme (Eqs. (4)-(6)). The constraints for the independent variables were taken as the minimum and maximum values of the culture conditions used in the experimental design (Table 1).

The Pareto optimization procedure yields 21 results, each in the format of Eq. (7). Each result is a point in the multi-dimensional design space identified by a set of independent variable values (medium composition and culture duration) and the corresponding three enzyme activities that would be observed if enzyme production was performed under the identified conditions. 
$\left[\right.$ Activity $_{\text {Lacopt }}$, Activity $_{\text {Bet } \mathrm{Opt}}$, Activity $\left._{\mathrm{Cmc} O p t}\right] @ f\left(A_{O p t}, B_{O p t}, C_{O p t}, D_{O p t}, E_{O p t}\right)$

Each of these points lies on the non-dominated Pareto frontier. This means, for the three activity values at each point, that there can be no further improvements in any one of them without compromise in one or both of the others. In other words, each point on the Pareto frontier is equivalent in terms of multi-objective optimality.

\subsubsection{Process simulation integration}

Without the inclusion of another criterion, it is not possible to distinguish the best option out of the Pareto optimal results if optimization of enzyme production is performed independently. In order to allow a quantified determination of the best result along the Pareto frontier, an additional criterion is needed. The estimated cost of each individual result can be considered as an additional criterion. Although selecting the result with the lowest estimated cost would be an option, this could still produce a suboptimal situation when the performance of the whole bioethanol production process is considered.

Each Pareto optimal result has a different combination of media composition and culture duration which would generate a different cost. Also, each result has a different combination of enzyme activities which would generate a different performance in the bioethanol production process. Therefore, multi-objective Pareto optimization should be integrated with bioethanol production simulation in order to quantify the cost-performance relationship.

2.2.3.1. Bioethanol process model. In a previously proposed process model (hereafter called $\mathrm{HH}$ Process), $\mathrm{HH}$ was used as the lignocellulosic feedstock for a bioethanol production process [23]. A simplified process flow diagram is shown in Fig. 1. In the HH Process, $\mathrm{HH}$ was steam-pretreated in a reaction vessel and cooled down before lignocellulolytic enzyme mixture containing Lac, Bet and $\mathrm{Cmc}$ was fed into the vessel. Lac acted as a biological pretreatment agent as a secondary pretreatment of $\mathrm{HH}$ (after steam pretreatment), while Bet and $\mathrm{Cmc}$ catalyzed lignocellulose hydrolysis. The ligninolytic effect of laccase was shown previously by our group [22] and others [38,39]. Following the hydrolysis step, hydrolysate (as C source), peptone and yeast extract (as organic $\mathrm{N}$ sources) were fed into the fermentation vessel. Crude fermentation product (including bioethanol) was filtered through microfiltration and this filtrate was then distilled for final product recovery which was bioethanol with $95.5 \%$ alcohol content. All the design preferences, unit operation selections, and assumptions were taken from the referenced publication. The adopted model was used to run simulations without any changes from its original version, except enzyme cost and enzyme performance.

In the HH Process model, cost of enzyme mixture to hydrolyze $90 \%$ of the $\mathrm{HH}$ into fermentable sugars was assumed to be $2 \$ / \mathrm{kg}$. These values represent the best-case scenario since they are given as feasibility targets in [23]. In other words, the target for an enzyme improvement program would be to achieve the production of an enzyme mixture at $2 \$ / \mathrm{kg}$. The enzyme mixture would hydrolyze $90 \%$ of the HH.

2.2.3.2. Enzyme performance and cost integration. Optimization of enzyme production and the bioethanol production process are linked via the cost of the enzyme mixture (EC) and efficiency of the conversion achieved using the enzyme mixture (CE). The optimized conditions are assumed to dictate enzyme cost whereas conversion efficiency is taken as a function of the three activities achieved under the optimized conditions.

$E C=f\left(A_{O p t}, B_{O p t}, C_{O p t}, D_{O p t}, E_{O p t}\right)$

$C E=f\left(\right.$ Activity $_{\text {Lacopt }}$, Activity $_{\text {Betopt }}$, Activity $\left._{\text {Cmcopt }}\right)$

$90 \%$ conversion (value used in the bioethanol model) is assumed to be the best-case scenario when the maximum observed activities for each enzyme is considered $\left(\mathrm{Lac}_{\max }\right.$, $\mathrm{Bet}_{\max }, \mathrm{Cmc}_{\max }$ ). So, optimization of enzyme production provides a possible reduction of the cost of enzyme from a maximum of $2 \$ / \mathrm{kg}$. The $2 \$ / \mathrm{kg}$ cost is assumed to occur when maximum values of each operational condition is used e.g. $A=20$, $B=10, C=20, D=20$, and $E=7$. Each of these factors are taken to affect the cost equally.

Each Pareto-optimal result involves optimal values for the operational conditions $\left(\mathrm{A}_{\mathrm{opt}}, \mathrm{B}_{\mathrm{opt}}, \mathrm{C}_{\mathrm{opt}}, \mathrm{D}_{\mathrm{opt}}, \mathrm{E}_{\mathrm{opt}}\right)$ and accompanying activities achieved for the three enzymes $\left(\mathrm{Lac}_{\mathrm{opt}}, \mathrm{Bet}_{\mathrm{opt}}, \mathrm{Cmc}_{\mathrm{opt}}\right)$. Because the production is a one-pot synthesis of the three enzymes together, it is not
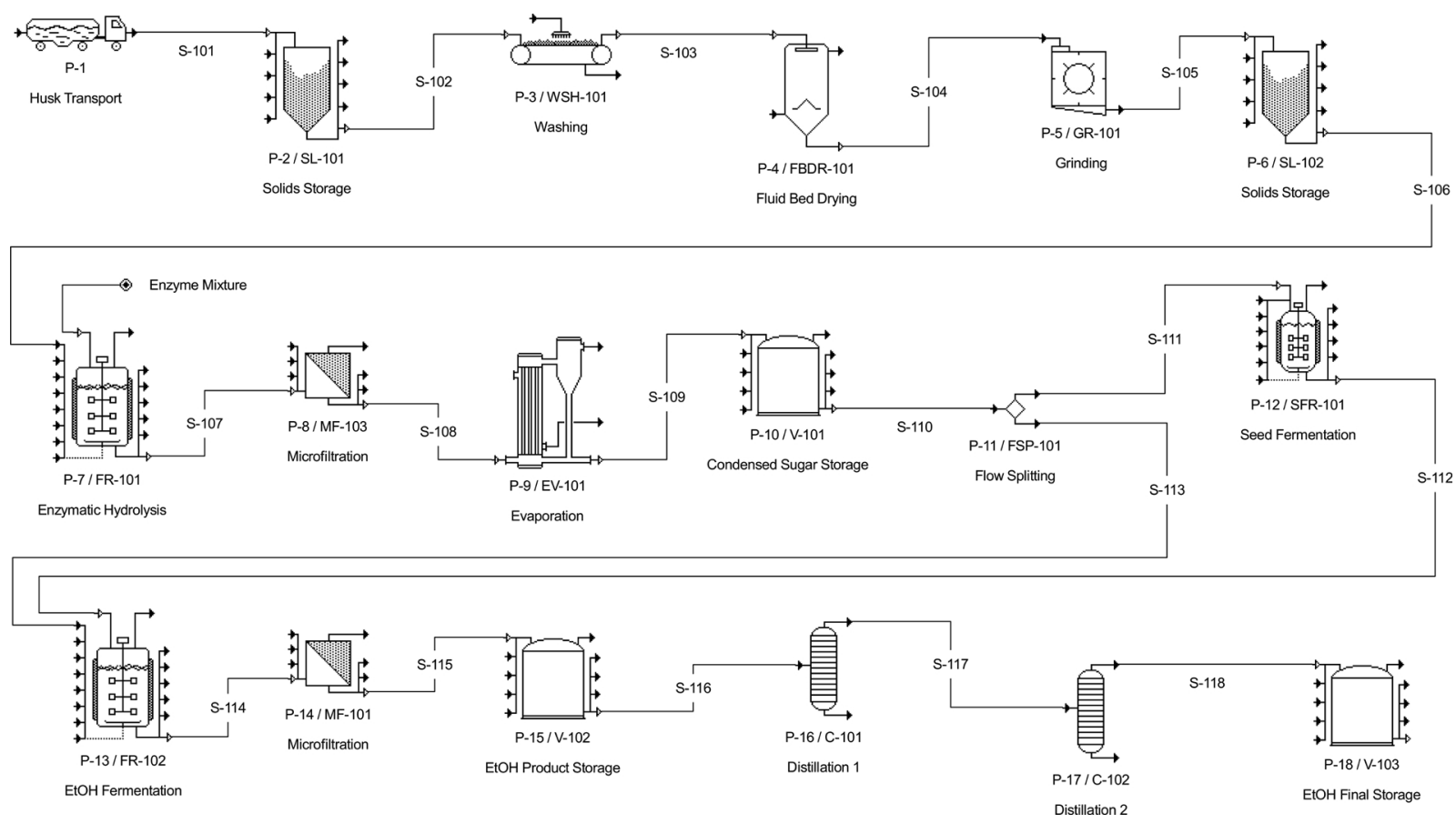

Fig. 1. Simplified PFD of HH Process. 
possible to obtain optimal activities as high as those that could be obtained if conditions were optimized for each enzyme individually. How far the optimal activities of each enzyme are from their respective maximums is assumed to affect the overall conversion. Each enzyme is assumed to affect the overall conversion equally.

Following scheme is applied to calculate $\mathrm{EC}$ and $\mathrm{CE}$ :

$A_{\text {max }}=20 ; B_{\text {max }}=10 ; C_{\text {max }}=20 ; D_{\max }=20 ; E_{\max }=7$ (maximum values from experimental design)

Weight $_{\mathrm{A}}=$ Weight $_{\mathrm{B}}=$ Weight $_{\mathrm{C}}=$ Weight $_{\mathrm{D}}=$ Weight $_{\mathrm{E}}=0.2($ each condition has an equal effect)

$\operatorname{coef}_{\mathrm{A}}=\mathrm{A}_{\mathrm{opt}} / \mathrm{A}_{\max }$

$\operatorname{coef}_{\mathrm{B}}=\mathrm{B}_{\mathrm{opt}} / \mathrm{B}_{\max }$

$\operatorname{coef}_{\mathrm{C}}=\mathrm{C}_{\text {opt }} / \mathrm{C}_{\max }$

$\operatorname{coef}_{\mathrm{D}}=\mathrm{D}_{\mathrm{opt}} / \mathrm{D}_{\max }$

$\operatorname{coef}_{\mathrm{E}}=\mathrm{E}_{\mathrm{opt}} / \mathrm{E}_{\max }$

$\mathrm{EC}=\$ 2 / \mathrm{kg} *$ Weight $_{\mathrm{A}} * \operatorname{coef}_{\mathrm{A}}+$ Weight $_{\mathrm{B}} * \operatorname{coef}_{\mathrm{A}}+$ Weight $_{\mathrm{C}} * \operatorname{coef}_{\mathrm{C}}+$ Weight $_{\mathrm{D}}{ }^{*} \operatorname{coef}_{\mathrm{D}}+$ Weight $_{\mathrm{E}}{ }^{*} \operatorname{coef}_{\mathrm{E}}$ )

$\mathrm{Lac}_{\max }=581.7 ; \mathrm{Bet}_{\max }=111.9 ; \mathrm{Cmc}_{\max }=382.2$ (maximum activity values obtained in experiments)Weight $t_{\text {Lac }}=$ Weight $_{\text {Bet }}=$ Weight $_{C m c}=1 / 3$ (each enzyme has an equal effect)

$\operatorname{coef}_{\text {Lac }}=\mathrm{Lac}_{\text {opt }} / \mathrm{Lac}_{\text {max }}$

$\operatorname{coef}_{\text {Bet }}=$ Bet $_{\text {opt }} /$ Bet $_{\text {max }}$

$\operatorname{coef}_{\mathrm{Cmc}}=\mathrm{Cmc}_{\text {opt }} / \mathrm{Cmc}_{\max }$

$\mathrm{CE}=90 \% *$ Weight $_{\text {Lac }}{ }^{*}$ coef $_{\text {Lac }}+$ Weight $_{\text {Bet }} * \operatorname{coef}_{\text {Bet }}+$ Weight $_{\text {Cmc }}$ * ${ }^{\circ}$ fof $_{\text {Cmc }}$ )

The calculated EC and CE were then fed into the bioethanol process model to calculate the net present value (NPV) of the process as described in [23].

\section{Results and discussion}

\subsection{Enzyme activities}

The activities of the three enzymes measured in the six exploratory experiments were tabulated in Table 3. Maximum activity of Lac (581.7 $\mathrm{U} / \mathrm{L}$ ) was observed in medium containing malt extract (ME) as additional nitrogen source. Maximum $\mathrm{Cmc}$ activity (382.2 U/L) was observed in medium containing peptone $(\mathrm{P})$ as the sole nitrogen source and maximum Bet activity (111.9 U/L) was observed in the medium containing yeast extract (YE) and sodium nitrate (SN). The maximum activities of the three enzymes were all obtained the on 7th day of production. Arora and Sharma (2011) investigated the effect of nitrogen sources for bioprocessing of wheat straw in solid-state fermentation (SSF) via $P$. brevispora and reported that although digestibility increased with ME supplement, it also decreased the total organic content (TOC) by $18.8 \%$. They concluded that increase in digestibility and decrease in TOC might be attributed to increase in biomass since $\mathrm{ME}$ is rich in simple sugar amino acids [29]. Moreover, Teoh et al. (2011) conducted a study to investigate the optimum medium composition for mycelial growth and antifungal activity of $P$. sanguineus. In this work, they found out that $10 \mathrm{~g} / \mathrm{l} \mathrm{ME}$, YE, dextrose and maltose supported the highest fungal growth [27]. In the presence of readily available reducing sugar, fungi produce high levels of Lac enzyme [40]. In our experimental results, it is also seen that presence of ME led to increased levels of Lac activity, compared to other supplements. Increased biomass production could also be the reason of increased activity of Lac. Increased biomass production means increased enzyme activity due to cumulative effect of each cell's production.

Kachlishvili et al. (2006) stated that highest Cmc activity was observed with the medium containing beech tree supplemented with peptone during SSF via $P$. dryinus IBB 903, $P$. tuberregium IBB 624 and $L$. edodes IBB 363, which are members of Basidiomycota as $P$. sanguineus DSMZ 3024 [41]. In experiments containing ME, no significant change in $\mathrm{Cmc}$ activity was observed as time progressed. Since there is more than $60 \%$ maltose in ME [42], this medium is a suitable environment for the growth of $P$. sanguineus which was already grown on MEA for preparation of spore suspension. Therefore, the fungus had potentially readily expressed enzymes to degrade maltose. As fungal biomass increased, microbial degradation of $\mathrm{HH}$ increased too. This degradation could be leading to the extraction of phenolic compounds from $\mathrm{HH}$ as similarly observed by others [43].

Bet production media usually do not contain organic nitrogen source with some exceptions [44]. Most of the medium optimization studies for Bet production were done with the medium composed of lignocellulosic biomass impregnated with suitable salts (modified versions of minimal Czapek, Mandel and Reese medium etc) to induce Bet production. In our study, highest Bet activity was observed in Experiment 5, which contained SN as inorganic nitrogen source and YE as organic nitrogen source. When Experiments 5 and 6 were compared, it was obvious that Bet activities of Experiment 5 were higher than Experiment 6. During sterilization of the medium containing $\mathrm{HH}$ (which can be accepted as "partial" hydrothermal pretreatment of feedstock), phenolics and furan derivatives might have leaked to the medium. It was stated in $[45,46]$ that hydrothermal pretreatment methods of lignocellulosic biomass release furan derivatives and phenolics. Phenolic acids, such as tannic and gallic acid inhibited the Bet activity in Trichoderma reesei [46]. Some studies in the literature state the possibility of Bet adsorption onto lignin [47] and inhibition of this adsorption is possible with addition of soybean protein [48]. YE might have caused a similar effect. Moreover, when all other experiments containing YE were analyzed, it was observed that presence of YE led to increased Bet activities in all cases (Table 3). Therefore, besides being a rich amino acid, vitamin and mineral source for microbial growth and maintenance of vitality, presence of YE might be presumed as a blocker for Bet adsorption onto lignin.

Table 3

Results of exploratory experiments.

\begin{tabular}{|c|c|c|c|c|c|c|c|c|c|c|c|c|c|c|c|c|c|c|}
\hline \multirow[t]{2}{*}{ Days } & \multicolumn{3}{|c|}{ Experiment 1} & \multicolumn{3}{|c|}{ Experiment 2} & \multicolumn{3}{|c|}{ Experiment 3} & \multicolumn{3}{|c|}{ Experiment 4} & \multicolumn{3}{|c|}{ Experiment 5} & \multicolumn{3}{|c|}{ Experiment 6} \\
\hline & $\mathrm{Lac}$ & Bet & $\mathrm{Cmc}$ & Lac & Bet & $\mathrm{Cmc}$ & Lac & Bet & $\mathrm{Cmc}$ & Lac & Bet & $\mathrm{Cmc}$ & Lac & Bet & $\mathrm{Cmc}$ & Lac & Bet & $\mathrm{Cmc}$ \\
\hline 0 & 0.0 & 0.0 & 114.6 & 0.0 & 0.0 & 114.6 & 0.0 & 0.0 & 189.9 & 0.0 & 0.0 & 344.7 & 0.0 & 0.0 & 195.9 & 0.0 & 0.0 & 137.2 \\
\hline 1 & 7.6 & 0.8 & 112.2 & 6.3 & 0.7 & 117.0 & 13.0 & 0.1 & 220.5 & 12.9 & 1.2 & 264.5 & 5.6 & -13.2 & 194.8 & 2.8 & -32.6 & 143.4 \\
\hline 2 & 14.9 & 2.9 & 142.2 & 29.7 & 4.2 & 105.0 & 75.7 & 3.3 & 234.1 & 61.3 & 1.7 & 326.2 & 16.4 & 10.5 & 182.1 & 7.7 & -40.7 & 134.1 \\
\hline 3 & 24.6 & 17.8 & 139.0 & 59.1 & 36.0 & 127.4 & 131.7 & 14.4 & 243.9 & 92.3 & 18.3 & 296.4 & 28.9 & 35.6 & 186.4 & 12.4 & -60.0 & 120.2 \\
\hline 4 & 39.1 & 44.8 & 178.3 & 64.4 & 41.1 & 129.0 & 153.9 & 31.2 & 222.8 & 75.6 & 43.2 & 349.9 & 29.8 & 67.8 & 152.7 & 22.3 & -52.9 & 131.8 \\
\hline 5 & 35.5 & 28.9 & 237.5 & 50.6 & 51.6 & 144.6 & 54.3 & 42.9 & 312.3 & 111.1 & 7.0 & 168.8 & 32.9 & 86.1 & 183.8 & 29.9 & -36.3 & 166.5 \\
\hline 6 & 35.1 & 27.5 & 317.7 & 50.0 & 60.3 & 155.8 & 39.1 & 51.7 & 243.4 & 255.3 & 6.7 & 267.1 & 29.1 & 89.2 & 223.0 & 31.7 & -32.2 & 131.0 \\
\hline 7 & 69.0 & 30.4 & 382.2 & 48.9 & 52.9 & 159.4 & 102.1 & 49.8 & 365.8 & 581.7 & 26.2 & 276.3 & 30.1 & 111.9 & 242.3 & 32.9 & -18.7 & 143.4 \\
\hline
\end{tabular}




\subsection{Activity models}

Generally, exploratory experiments, such as those performed in this study, give preliminary insights into the nature of the new lignocellulolytic enzyme producing organism like those mentioned in the previous section. Subsequently, a new set of experiments were design based on the insights gained. The experimental design often follows a conventional statistical design of experiments approach such as response surface methodology. The primary objective of these experiments is the optimization of enzyme production. Usually they are static experiments with no temporal data. The data is then used to generate low order polynomial models of optimization objective functions (enzyme activities) which can be used in numerical optimization schemes.

Recently, it was shown that a different type of modeling approach, namely Kriging, allows the generation of models to be used in numerical optimization, using the time profile data from the exploratory experiments without the need to perform dedicated static experiments [35]. Accordingly, for this study, three Kriging-based models were generated for each enzyme activity as a function of the five enzyme production operating conditions. All three models showed good model statistics as tabulated in Table 4 . The $\mathrm{R}^{2}$ values indicate the percentage of experimental data variation explained by the models. Root mean square error values (RMSE) are a measure of the average deviations of model predictions from experimental values. The RMSE of Lac activity model was less than $1 \%$ of the maximum Lac activity observed. The RMSEs of $\mathrm{Cmc}$ and Bet activities were 5 and $7.7 \%$ of their respective maximums observed.

Fig. 2 shows the model predictions against experimental data, confirming the good fit between them. Lac activity model seems to be the best fitting with its respective experimental data. In comparison, Bet

Table 4

Model statistics for the three activity models.

\begin{tabular}{lll}
\hline Activity Model & $\mathrm{R}^{2}$ & RMSE \\
\hline Lac & 0.997 & 4.7125 \\
Bet & 0.975 & 5.6449 \\
Cmc & 0.847 & 29.77 \\
\hline
\end{tabular}

activity model shows very good fit for experiments 2,3 , 5, and 6 whereas the $4^{\text {th }}$ day activity measurements that belong to experiments 1 and 4 show a slight mismatch. This may be due to a possible change in the behavior of the organism initiated on that day in the P and ME containing media. Whatever that change may be, the model seems to have incorporated it in the following data points for those two experiments. Cmc activity model arguably represents the overall trends in all of the experiments albeit not as accurately as the Lac and Bet activity models (as shown by the $\mathrm{R}^{2}$ values). This can possibly be attributed to a higher number of uncontrolled factors affecting the Cmc activity assay compared to the Lac and Bet activity assays [43]. This is acceptable as long as a significant proportion of the overall experimental variation is explained by the model $\left(\mathrm{R}^{2}=0.85\right)$.

\subsection{Optimization}

The availability of activity models allows numerical optimization. The first part of the optimization workflow performs genetic algorithm based multi-objective optimization with the three activity models as objective functions. Five culture operating conditions (A-E) were optimized. 21 Pareto-optimal points were identified on the solution space. The resulting 3-D Pareto frontier is displayed in Fig. 3. Each Paretooptimal point provided five enzyme production conditions and the corresponding enzyme activities that would be achieved, as predicted by the activity models. All Pareto-optimal points were equivalent. Trying to improve one of the activities would necessarily cause a deterioration in the others. Eight leftmost columns of Table 6 summarize the results of multi-objective optimization.

Process simulation integration of multi-objective optimization results was performed twice. In the first instance, the effects of five operating conditions on the enzyme cost and the three activities on enzyme efficiency were taken to be equal as detailed above. In the second instance, the effect of culture duration was considered to be more significant compared to the medium component concentrations. Also, Bet activity was considered to be more important compared to the activities of Lac and Cmc. The weight schemes for the two cases are given in Table 5.

The results of the optimization are tabulated in Table 6. In Case 1, each enzyme production operating condition was assumed to have an


Fig. 2. Kriging model fit to experimental data. 


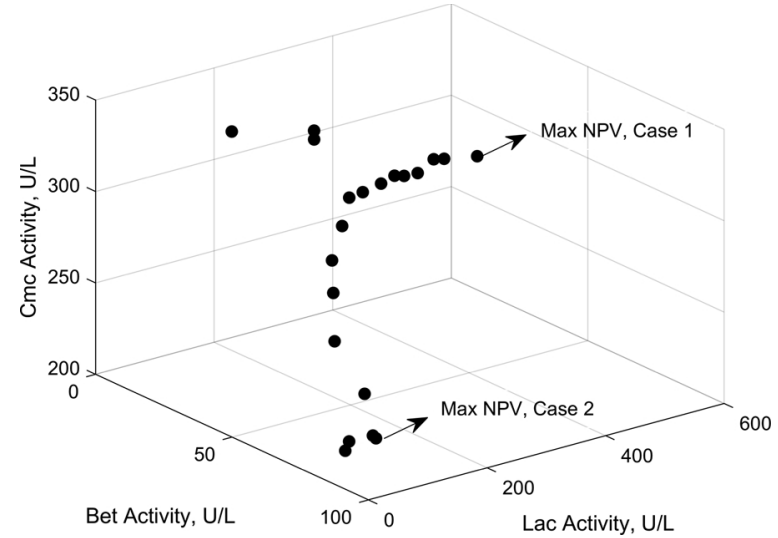

Fig. 3. 3-D Pareto frontier.

Table 5

Weight schemes for the two cases.

\begin{tabular}{lll}
\hline & Case 1 & Case 2 \\
\hline Weight $_{\mathrm{A}}$ & 0.2 & 0.1 \\
Weight $_{\mathrm{B}}$ & 0.2 & 0.1 \\
Weight $_{\mathrm{C}}$ & 0.2 & 0.1 \\
Weight $_{\mathrm{D}}$ & 0.2 & 0.1 \\
Weight $_{\mathrm{E}}$ & 0.2 & 0.6 \\
Weight $_{\text {Lac }}$ & $1 / 3$ & $0.5 / 3$ \\
Weight $_{\text {Bet }}$ & $1 / 3$ & $2 / 3$ \\
Weight $_{\text {Cmc }}$ & $1 / 3$ & $0.5 / 3$ \\
\hline
\end{tabular}

equal effect on the overall cost of enzyme production. This is a simplifying assumption to demonstrate the application of the workflow. In a different enzyme production system, the effects of different operating conditions on the cost of enzyme will vary. In Case 1, the Pareto-optimal result with the best simulated NPV is detailed in the fourth row of Table 6. NPV is simulated to be $\$ 76.1$ million. The enzyme production operating conditions for this result require minimum P $(1.1 \mathrm{~g} / \mathrm{L})$, YE $(0.2 \mathrm{~g} / \mathrm{L})$ and $\mathrm{SN}(0.4 \mathrm{~g} / \mathrm{L})$ use. ME is required near its maximum level $(19.8 \mathrm{~g} / \mathrm{L})$. Culture duration required was seven days.
In Case 2, culture duration is considered to be a more significant factor contributing to the cost of enzyme production. This is reasonable because a long culture requires an increased input of utilities and consumables while at the same time lowering productivity. Also, in Case 2, Bet activity is considered to have a more significant effect on the performance of the lignocellulolytic enzyme cocktail. Bet is usually the limiting enzyme in most lignocellulolytic enzyme mixtures [49-52], making this assumption a reasonable case to investigate. When necessary modifications were made to the weighing scheme to reflect the considerations of Case 2 (as detailed in Table 5), the Pareto-optimal result with the best simulated NPV changed, compared to Case 1. As in Case 1, minimum $\mathrm{P}$ and $\mathrm{SN}$ and maximum culture duration were required. However, in contrast to Case 1, Case 2 required maximal YE and minimal ME. In Case 2, simulated NPV was increased to \$106.6 million.

The response surfaces for Cases 1 and 2 relating the combined effects of yeast and malt extract concentrations in the enzyme mixture production on NPV of bioethanol production process are given in Fig. 4. Response surfaces for other combinations of culture ingredients can be found in Supplementary Materials.

\section{Conclusion}

We have developed and demonstrated a process simulation-integrated multi-objective optimization workflow for lignocellulolytic enzymes production. Time-profile data from six experiments with varying medium compositions were collected within an exploratory experimentation scheme. The data were used to generate enzyme activity models by Kriging for three lignocellulolytic enzymes, Lac, Bet, and $\mathrm{Cmc}$, as a function of medium composition and culture duration. We had previously shown that Kriging performs better compared to more conventional response surface methodology with temporal data sets from similar exploratory experiments. The generated models were used to perform multi-objective optimization of medium composition and culture duration using a Pareto-based approach. The Pareto-optimal results were linked via enzyme performance and enzyme cost functions to a bioethanol production process simulation which had been developed by our group before. The cases, where significance of enzyme production conditions affected bioethanol production differently, were analyzed with the process-simulation integrated

Table 6

Process simulation-integrated multi-objective optimization results.

\begin{tabular}{|c|c|c|c|c|c|c|c|c|c|c|c|c|c|}
\hline \multicolumn{5}{|c|}{ Pareto Optimal Operating Conditions for Enzyme Production } & \multicolumn{3}{|c|}{$\begin{array}{l}\text { Model Predicted Enzyme } \\
\text { Activities }\end{array}$} & \multicolumn{2}{|c|}{ Calculated CE (\%) } & \multicolumn{2}{|c|}{$\begin{array}{l}\text { Calculated EC } \\
(\$ / \mathrm{kg})\end{array}$} & \multicolumn{2}{|c|}{ Simulated NPV ( $\$$ mil) } \\
\hline $\begin{array}{l}\text { Peptone (g/ } \\
\text { L) }\end{array}$ & $\begin{array}{l}\text { Yeast } \\
\text { Extract }(\mathrm{g} / \mathrm{L})\end{array}$ & $\begin{array}{l}\text { Malt Extract } \\
(\mathrm{g} / \mathrm{L})\end{array}$ & $\begin{array}{l}\text { Sodium } \\
\text { Nitrate }(g / L)\end{array}$ & $\begin{array}{l}\text { Duration } \\
\text { (Days) }\end{array}$ & $\begin{array}{l}\text { Lac (U/ } \\
\text { L) }\end{array}$ & $\begin{array}{l}\text { Bet (U/ } \\
\text { L) }\end{array}$ & $\begin{array}{l}\text { Cmc (U/ } \\
\mathrm{L})\end{array}$ & Case 1 & Case 2 & Case 1 & Case 2 & Case 1 & Case 2 \\
\hline 20.0 & 0.5 & 6.9 & 0.6 & 7 & 143.7 & 18.7 & 333.0 & 38.6 & 26.8 & 0.97 & 1.48 & -38.1 & -148.0 \\
\hline 1.1 & 9.9 & 0.3 & 7.4 & 7 & 32.0 & 95.8 & 228.0 & 45.2 & 61.2 & 0.97 & 1.46 & 8.5 & 106.6 \\
\hline 5.3 & 9.7 & 0.6 & 10.5 & 7 & 48.3 & 81.0 & 209.6 & 40.7 & 52.9 & 1.11 & 1.52 & -20.8 & 56.0 \\
\hline 1.5 & 0.2 & 19.8 & 0.4 & 7 & 559.5 & 18.3 & 282.7 & 56.0 & 35.3 & 0.84 & 1.42 & 76.1 & -66.8 \\
\hline 2.1 & 7.6 & 19.5 & 2.9 & 7 & 363.4 & 30.6 & 297.7 & 50.3 & 37.5 & 1.19 & 1.60 & 40.7 & -49.3 \\
\hline 1.8 & 7.1 & 17.3 & 3.0 & 7 & 325.1 & 34.0 & 299.1 & 49.4 & 38.4 & 1.13 & 1.56 & 33.1 & -41.5 \\
\hline 0.2 & 9.7 & 0.7 & 7.6 & 7 & 29.1 & 95.3 & 229.4 & 45.1 & 60.9 & 0.94 & 1.43 & 7.4 & 104.9 \\
\hline 0.4 & 9.6 & 2.9 & 7.5 & 7 & 43.2 & 89.2 & 246.8 & 45.5 & 58.6 & 1.00 & 1.50 & 9.7 & 91.1 \\
\hline 1.2 & 9.0 & 6.3 & 6.8 & 7 & 72.7 & 71.8 & 261.0 & 43.5 & 50.6 & 1.03 & 1.49 & -2.2 & 42.2 \\
\hline 1.1 & 6.0 & 7.3 & 5.9 & 7 & 142.3 & 56.2 & 270.6 & 43.7 & 44.4 & 0.93 & 1.46 & -1.0 & 2.7 \\
\hline 17.2 & 0.5 & 15.9 & 0.7 & 7 & 322.6 & 10.0 & 311.8 & 43.8 & 25.9 & 1.09 & 1.53 & -0.5 & -156.8 \\
\hline 1.1 & 0.7 & 16.1 & 2.2 & 7 & 444.4 & 21.5 & 285.8 & 51.1 & 34.2 & 0.81 & 1.40 & 46.3 & -76.7 \\
\hline 2.0 & 8.5 & 15.3 & 2.1 & 7 & 247.9 & 39.1 & 301.7 & 47.0 & 39.2 & 1.13 & 1.56 & 18.4 & -34.3 \\
\hline 1.7 & 7.4 & 12.3 & 3.3 & 7 & 207.4 & 45.3 & 294.0 & 45.9 & 41.2 & 1.04 & 1.51 & 12.2 & -17.4 \\
\hline 2.1 & 7.9 & 16.2 & 2.7 & 7 & 280.4 & 37.0 & 300.4 & 48.0 & 38.8 & 1.14 & 1.57 & 24.5 & -37.5 \\
\hline 4.1 & 0.4 & 19.3 & 0.2 & 7 & 505.5 & 14.1 & 282.9 & 52.1 & 31.7 & 0.88 & 1.42 & 52.0 & -99.8 \\
\hline 4.8 & 9.7 & 0.7 & 8.3 & 7 & 45.6 & 83.0 & 216.3 & 41.6 & 54.2 & 1.05 & 1.49 & -13.7 & 63.9 \\
\hline 1.3 & 7.9 & 11.7 & 6.2 & 7 & 165.0 & 50.8 & 282.7 & 44.3 & 42.6 & 1.09 & 1.53 & 2.6 & -8.6 \\
\hline 1.8 & 4.6 & 17.3 & 3.0 & 7 & 388.8 & 28.6 & 294.0 & 50.8 & 36.9 & 1.03 & 1.51 & 44.0 & -53.7 \\
\hline 19.7 & 0.5 & 17.7 & 3.2 & 7 & 321.3 & 10.3 & 307.3 & 43.5 & 25.9 & 1.23 & 1.60 & -2.9 & -157.7 \\
\hline 1.5 & 0.2 & 17.3 & 0.4 & 7 & 498.7 & 19.4 & 287.4 & 53.5 & 53.5 & 0.79 & 1.39 & 60.9 & -73.7 \\
\hline
\end{tabular}



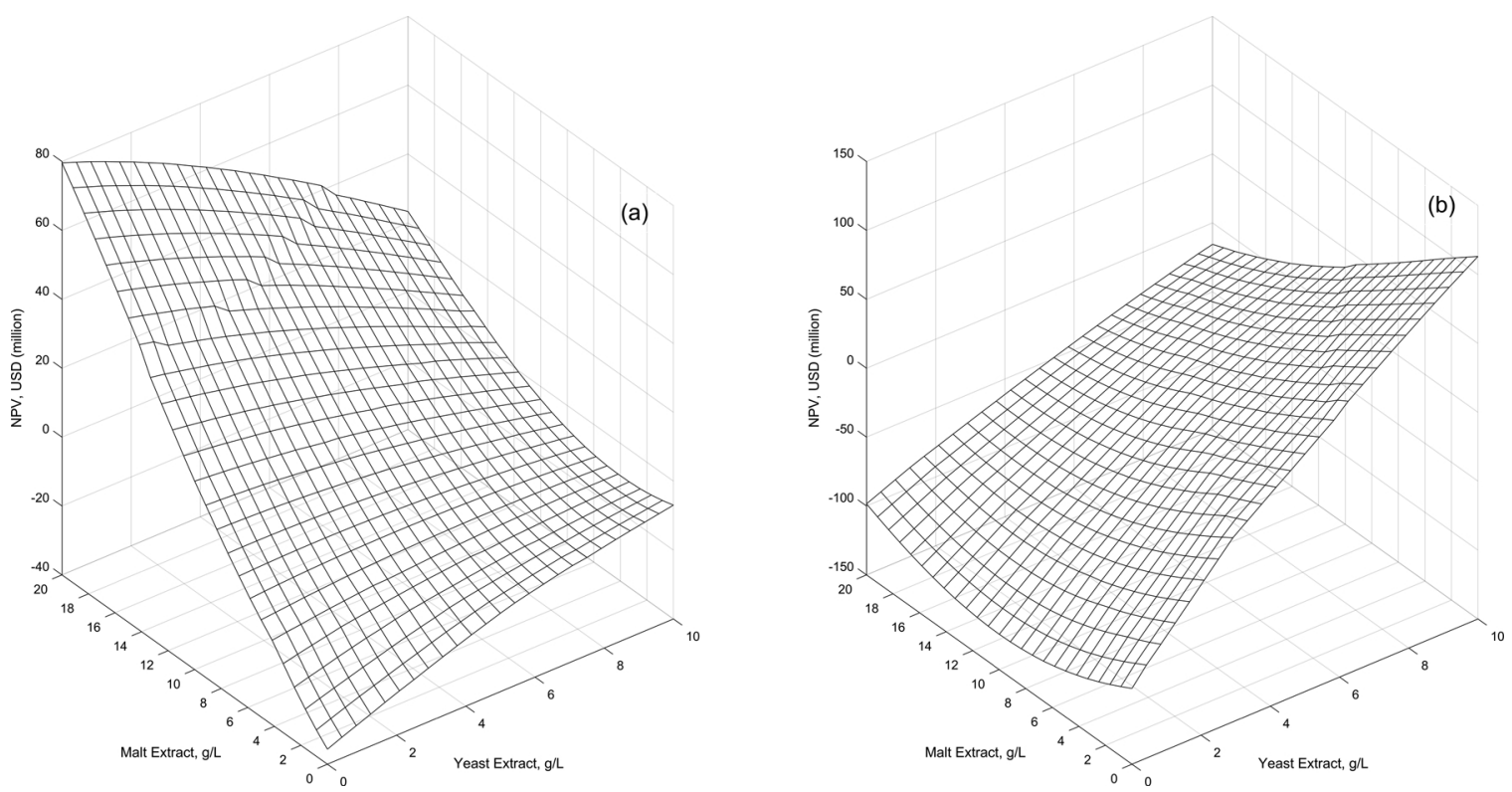

Fig. 4. Combined effect of YE and ME concentrations in enzyme production on the NPV of bioethanol production process; a) Case 1 b) Case 2.

optimization workflow. A shift from a ME to YE-dominated medium requirement was observed in Case 2 compared to Case 1 . This observation was made possible with the process simulation-integrated optimization workflow.

This demonstration hopefully highlights the importance of process simulation integration from the earliest stages of biocatalyst screening, selection, and optimization not only for lignocellulolytic enzyme production towards bioethanol manufacturing but also for the wider biocatalysis field. The present manuscript was intended as a demonstration of the concept. Many details entail further refinement not the least of which regards enzyme performance and cost calculations and related weighing schemes. This is the subject of ongoing studies by our group.

\section{Acknowledgments}

Funding was provided by Marmara University, Scientific Research Projects Committee (FEN-C-DRP-120917-0548).

\section{Appendix A. Supplementary data}

Supplementary material related to this article can be found, in the online version, at doi:https://doi.org/10.1016/j.bej.2019.107420.

\section{References}

[1] S. Chovau, D. Degrauwe, B. Van Der Bruggen, Critical analysis of techno-economic estimates for the production cost of lignocellulosic bio-ethanol, Renewable Sustainable Energy Rev. (2013), https://doi.org/10.1016/j.rser.2013.05.064.

[2] V. Balan, Current challenges in commercially producing biofuels from lignocellulosic biomass, ISRN Biotechnol. (2014), https://doi.org/10.1155/2014/ 463074.

[3] D. Klein-Marcuschamer, P. Oleskowicz-Popiel, B.A. Simmons, H.W. Blanch, The challenge of enzyme cost in the production of lignocellulosic biofuels, Biotechnol. Bioeng. 109 (2012) 1083-1087, https://doi.org/10.1002/bit.24370.

[4] G. Liu, J. Zhang, J. Bao, Cost evaluation of cellulase enzyme for industrial-scale cellulosic ethanol production based on rigorous Aspen Plus modeling, Bioprocess Biosyst. Eng. 39 (2016) 133-140, https://doi.org/10.1007/s00449-015-1497-1.

[5] N.A. Boakye-Boaten, L. Kurkalova, S. Xiu, A. Shahbazi, Techno-economic analysis for the biochemical conversion of Miscanthus x giganteus into bioethanol, Biomass Bioenergy 98 (2017) 85-94, https://doi.org/10.1016/j.biombioe.2017.01.017.

[6] A. Hasanly, M. Khajeh Talkhoncheh, M. Karimi Alavijeh, Techno-economic assessment of bioethanol production from wheat straw: a case study of Iran, Clean Technol. Environ. Policy. 20 (2018) 357-377, https://doi.org/10.1007/s10098017-1476-0.

[7] G. Banerjee, S. Car, J.S. Scott-Craig, M.S. Borrusch, M. Bongers, J.D. Walton, Synthetic multi-component enzyme mixtures for deconstruction of lignocellulosic biomass, Bioresour. Technol. 101 (2010) 9097-9105, https://doi.org/10.1016/j. biortech.2010.07.028.

[8] R.R. Singhania, R.K. Sukumaran, A.K. Patel, C. Larroche, A. Pandey, Advancement and comparative profiles in the production technologies using solid-state and submerged fermentation for microbial cellulases, Enzyme Microb. Technol. (2010), https://doi.org/10.1016/j.enzmictec.2010.03.010.

[9] Y.H. Percival Zhang, M.E. Himmel, J.R. Mielenz, Outlook for cellulase improvement: screening and selection strategies, Biotechnol. Adv. (2006), https://doi.org/ 10.1016/j.biotechadv.2006.03.003.

[10] D. Deswal, Y.P. Khasa, R.C. Kuhad, Optimization of cellulase production by a brown rot fungus Fomitopsis sp. RCK2010 under solid state fermentation, Bioresour. Technol. 102 (2011) 6065-6072, https://doi.org/10.1016/j.biortech.2011.03.032.

[11] F.F. Sun, J. Hong, J. Hu, J.N. Saddler, X. Fang, Z. Zhang, S. Shen, Accessory enzymes influence cellulase hydrolysis of the model substrate and the realistic lignocellulosic biomass, Enzyme Microb. Technol. 79-80 (2015) 42-48, https://doi. org/10.1016/J.ENZMICTEC.2015.06.020.

[12] J. Hu, V. Arantes, A. Pribowo, J.N. Saddler, The synergistic action of accessory enzymes enhances the hydrolytic potential of a "cellulase mixture" but is highly substrate specific, Biotechnol. Biofuels 6 (2013) 112, https://doi.org/10.1186/ 1754-6834-6-112.

[13] F. Fenila, Y. Shastri, Optimal control of enzymatic hydrolysis of lignocellulosic biomass, Bioresour. Technol. Rep. 2 (2016) S96-S104, https://doi.org/10.1016/J. REFFIT.2016.11.006.

[14] A. Berlin, V. Maximenko, N. Gilkes, J. Saddler, Optimization of enzyme complexes for lignocellulose hydrolysis, Biotechnol. Bioeng. 97 (2007) 287-296, https://doi. org $/ 10.1002 /$ bit.21238.

[15] P. Ib, R. Chauhan, Effect of carbon and nitrogen sources on the growth, reproduction and ligninolytic enzymes activity of dictyoarthrinium synnematicum somrith, Adv. Zool. Bot. 3 (2015) 24-30, https://doi.org/10.13189/azb.2015. 030203.

[16] R. Kumar Sharma, D. Singh Arora, Fungal degradation of lignocellulosic residues: an aspect of improved nutritive quality, Crit. Rev. Microbiol. 41 (2015) 52-60, https://doi.org/10.3109/1040841X.2013.791247.

[17] Hemansi, R. Gupta, R.C. Kuhad, J.K. Saini, Cost effective production of complete cellulase system by newly isolated Aspergillus niger RCKH-3 for efficient enzymatic saccharification: medium engineering by overall evaluation criteria approach (OEC), Biochem. Eng. J. 132 (2018) 182-190, https://doi.org/10.1016/j.bej.2018. 01.019.

[18] A. Mitsos, N. Asprion, C.A. Floudas, M. Bortz, M. Baldea, D. Bonvin, A. Caspari, P. Schäfer, Challenges in process optimization for new feedstocks and energy sources, Comput. Chem. Eng. 113 (2018) 209-221, https://doi.org/10.1016/j. compchemeng.2018.03.013.

[19] A. Aden, T. Foust, Technoeconomic analysis of the dilute sulfuric acid and enzymatic hydrolysis process for the conversion of corn stover to ethanol, Cellulose 16 (2009) 535-545, https://doi.org/10.1007/s10570-009-9327-8.

[20] Z. Barta, K. Kovacs, K. Reczey, G. Zacchi, Process design and economics of on-site cellulase production on various carbon sources in a softwood-based ethanol plant, Enzyme Res. 2010 (2010), https://doi.org/10.4061/2010/734182 734182.

[21] P. Jampala, P. Murugan, S. Ramanujam, K.B. Uppuluri, Investigation on the effect of carbon and nitrogen sources for the production of cellulosome by Trichoderma reesei NCIM 1186 using saturated placket burman design, Biosci. Biotechnol. Res. Asia 12 (2015) 1577-1586, https://doi.org/10.13005/bbra/1819.

[22] O. Pinar, K. Karaosmanoğlu, N.A. Sayar, C. Kula, D. Kazan, A.A. Sayar, Assessment of hazelnut husk as a lignocellulosic feedstock for the production of fermentable sugars and lignocellulolytic enzymes, 3 Biotech. 7 (2017) 367, https://doi.org/10. 
1007/s13205-017-1002-4.

[23] N.A. Sayar, O. Pinar, D. Kazan, A.A. Sayar, Bioethanol Production From Turkish Hazelnut Husk Process Design and Economic Evaluation, Waste Biomass Valorization (2017) 1-15, https://doi.org/10.1007/s12649-017-0103-y.

[24] V. Bhaskar, S.K. Gupta, A.K. Ray, Applications of multiobjective optimization in chemical engineering, Int. Rev. Chem. Eng. 16 (2000) 1-54, https://doi.org/10. 1515/REVCE.2000.16.1.1.

[25] M.E. Eugenio, J.M. Carbajo, J.A. Martín, A.E. González, J.C. Villar, Laccase production by Pycnoporus sanguineus under different culture conditions, J. Basic Microbiol. 49 (2009) 433-440, https://doi.org/10.1002/jobm.200800347.

[26] O.A. Ogunyewo, F.M. Olajuyigbe, Unravelling the interactions between Hydrolytic and oxidative enzymes in degradation of lignocellulosic biomass by Sporothrix carnis under various fermentation conditions, Biochem. Res. Int. 2016 (2016), https://doi.org/10.1155/2016/1614370.

[27] Y.P. Teoh, M.M. Don, S. Ujang, Media selection for mycelia growth, antifungal activity against wood-degrading fungi, and GC-MS study by Pycnoporus sanguineus, Bio. Resour. 6 (2011) 2719-2731 (Accessed 11 August 2017), https:// bioresources.cnr.ncsu.edu/BioRes_06/BioRes_06_3_2719_Teoh_DU_Media_Mycelia Antifungal_GCMS_Pycnoporus_1752.pdf.

[28] N. Mikiashvili, S.P. Wasser, E. Nevo, V. Elisashvili, Effects of carbon and nitrogen sources on Pleurotus ostreatus ligninolytic enzyme activity, World J. Microbiol. Biotechnol. 22 (2006) 999-1002, https://doi.org/10.1007/s11274-006-9132-6.

[29] D.S. Arora, R.K. Sharma, Effect of different supplements on bioprocessing of wheat straw by Phlebia brevispora: changes in its chemical composition, in vitro digestibility and nutritional properties, Bioresour. Technol. 102 (2011) 8085-8091, https://doi.org/10.1016/j.biortech.2011.06.007.

[30] E.D. Morales-Álvarez, C.M. Rivera-Hoyos, Á.M. Cardozo-Bernal, R.A. PoutouPiñales, A.M. Pedroza-Rodríguez, D.J. Díaz-Rincón, A. Rodríguez-López, C.J. Alméciga-Díaz, C.L. Cuervo-Patiño, Plackett-burman design for rGILCC1 laccase activity enhancement in pichia pastoris: concentrated enzyme kinetic characterization, Enzyme Res. 2017 (2017), https://doi.org/10.1155/2017/5947581.

[31] O. García-Kirchner, M. Segura-Granados, P. Rodríguez-Pascual, Effect of media composition and growth conditions on production of $\beta$-Glucosidase by Aspergillus niger C-6, Appl. Biochem. Biotechnol. 121 (2005) 0347-0360, https://doi.org/10. 1385/abab:121:1-3:0347.

[32] T.K. Ghose, Measurements of cellullase activities, Pure Appl. Chem. (1987).

[33] J.P.C. Kleijnen, Regression and Kriging metamodels with their experimental designs in simulation: a review, Eur. J. Oper. Res. 256 (2017) 1-16, https://doi.org/10. 1016/j.ejor.2016.06.041

[34] B. Keshtegar, C. Mert, O. Kisi, Comparison of four heuristic regression techniques in solar radiation modeling: kriging method vs RSM, MARS and M5 model tree, Renewable Sustainable Energy Rev. 81 (2018) 330-341, https://doi.org/10.1016/ J.RSER.2017.07.054.

[35] C. Kula, N.A. Sayar, International Journal of Green Energy Multi-objective optimization of a novel crude lipase-catalyzed fatty acid methyl ester (FAME) production using low-order polynomial and Kriging models Multi-objective optimization of a novel crude lipase-catalyzed fat, Int. J. Green Energy 16 (2019) 657-665, https://doi.org/10.1080/15435075.2019.1608443.

[36] A.I. Khuri, S. Mukhopadhyay, Response surface methodology, Wiley Interdiscip, Rev. Comput. Stat. 2 (2010) 128-149, https://doi.org/10.1002/wics.73.

[37] H.B. Nielsen, J. Søndergaard, Dace-A Matlab Kriging Toolbox Version 2.0 Søren N. Lophaven, (2002) (Accessed 17 May 2019), http://citeseerx.ist.psu.edu/viewdoc/ download? doi $=10.1 \cdot 1 \cdot 73.5824 \&$ rep $=$ rep $1 \&$ type $=$ pdf

[38] M. Bilal, M. Asgher, H.M.N. Iqbal, H. Hu, X. Zhang, Biotransformation of lignocellulosic materials into value-added products-a review, Int. J. Biol. Macromol. 98 (2017) 447-458, https://doi.org/10.1016/j.ijbiomac.2017.01.133.

[39] I. Isroi, R. Millati, C. Niklasson, C. Cayanto, M.J. Taherzadeh, K. Lundquist, Biological treatment of Lignocelluloses with white-rot funghi and its applications: review, Bio. Resour. 6 (2011) 5224-5259, https://doi.org/10.15376/biores.6.4. 5224-5259.

[40] A. Piscitelli, P. Giardina, V. Lettera, C. Pezzella, G. Sannia, V. Faraco, Induction and transcriptional regulation of laccases in Fungi, Curr. Genomics 12 (2011) 104-112, https://doi.org/10.2174/138920211795564331.

[41] E. Kachlishvili, M. Penninckx, N. Tsiklauri, V. Elisashvili, Effect of nitrogen source on lignocellulosic enzyme production by white-rot basidiomycetes under solid-state cultivation, Artic. World J. Microbiol. Biotechnol. (2006), https://doi.org/10.1007/ s11274-005-9046-8.

[42] Malt extract for microbiology | Sigma-Aldrich, (n.d.). https://www.sigmaaldrich. $\mathrm{com} / \mathrm{catalog} / \mathrm{product} / \mathrm{sial} / 70167$ ?lang $=$ en\&region $=$ TR. (accessed September 11, 2018).

[43] D.B. Rivers, S.J. Gracheck, L.C. Woodford, G.H. Emert, Limitations of the DNS assay for reducing sugars from saccharified lignocellulosics, Biotechnol. Bioeng. 26 (1984) 800-802, https://doi.org/10.1002/bit.260260727.

[44] L.M. Dias, B.V. dos Santos, C.J.B. Albuquerque, B.E.L. Baeta, D. Pasquini, M.A. Baffi, Biomass sorghum as a novel substrate in solid-state fermentation for the production of hemicellulases and cellulases by Aspergillus niger and A. Fumigatus, J. Appl. Microbiol. 124 (2018) 708-718, https://doi.org/10.1111/jam.13672.

[45] J.K. Ko, Y. Um, Y.-C. Park, J.-H. Seo, K.H. Kim, Compounds inhibiting the bioconversion of hydrothermally pretreated lignocellulose, Appl. Microbiol. Biotechnol. 99 (2015) 4201-4212, https://doi.org/10.1007/s00253-015-6595-0.

[46] Y. Kim, E. Ximenes, N.S. Mosier, M.R. Ladisch, Soluble inhibitors/deactivators of cellulase enzymes from lignocellulosic biomass, Enzyme Microb. Technol. 48 (2011) 408-415, https://doi.org/10.1016/J.ENZMICTEC.2011.01.007.

[47] M.O. Haven, H. Jørgensen, Adsorption of $\beta$-glucosidases in two commercial preparations onto pretreated biomass and lignin, Biotechnol. Biofuels 6 (2013) 165 https://doi.org/10.1186/1754-6834-6-165.

[48] C. Florencio, A.C. Badino, C.S. Farinas, Addition of soybean protein improves saccharification and ethanol production from hydrothermally pretreated sugarcane bagasse, Bioenergy Res. 12 (2019) 81-93, https://doi.org/10.1007/s12155-0189956-6.

[49] V.R. Saritha Mohanram, Beta-glucosidase: key enzyme in determining efficiency of cellulase and biomass hydrolysis, J. Bioprocess Biotech. 05 (2015), https://doi.org/ 10.4172/2155-9821.1000197.

[50] G.H. Hansen, M. Lübeck, J.C. Frisvad, P.S. Lübeck, B. Andersen, Production of cellulolytic enzymes from ascomycetes: Comparison of solid state and submerged fermentation, Process Biochem. 50 (2015) 1327-1341, https://doi.org/10.1016/j. procbio.2015.05.017.

[51] P.S. Lübeck, M. Lübeck, Discovery of a novel fungus with an extraordinary $\beta$-glucosidase and potential for on-site production of High value products, Methods in Molecular Biology, Humana Press, New York, NY, 2018, pp. 25-33, https://doi.org/ 10.1007/978-1-4939-7877-9_2.

[52] L. Thomas, C. Larroche, A. Pandey, Current developments in solid-state fermentation, Biochem. Eng. J. 81 (2013) 146-161, https://doi.org/10.1016/J.BEJ.2013.10. 013. 